\title{
PRIMARY NON-RESPONSE IN INFLAMMATORY BOWEL DISEASE, DEFINITION, POTENTIAL CAUSES, THERAPEUTIC DRUG MONITORING AND MICROBIOTA - A REVIEW
}

\author{
Alatawi, H..$^{1,2^{*}}$ - Mosli, M. ${ }^{3,5}$ - SAADAH, O.$^{4,5}$ - DUlai, P. S. ${ }^{6}$ - Al-Hindi, R. R. ${ }^{1}-$ \\ BAHIELDIN, A. ${ }^{1,7}-$ EDRIS, S..$^{1,7,8}$ \\ ${ }^{1}$ Department of Biological Sciences, Faculty of Science, King Abdulaziz University, Jeddah \\ 21589, Saudi Arabia \\ (phone/fax: +966-2-460-0000) \\ ${ }^{2}$ Department of Biological Sciences, University Collage of Haqel, University of Tabuk, Tabuk, \\ Saudi Arabia \\ ${ }^{3}$ Department of Medicine, King Abdulaziz University, Jeddah, Saudi Arabia \\ (phone: +966-12-640-8272; fax: +966-12-695-2538) \\ ${ }^{4}$ Department of Pediatrics, Faculty of Medicine, King Abdulaziz University, Jeddah, Saudi \\ Arabia \\ (phone: +966-12-640-8272; fax: +966-12-695-2538) \\ ${ }^{5}$ Inflammatory Bowel Disease Research Group, King Abduklaziz University, Jeddah, Saudi \\ Arabia \\ (phone: +966-12-640-8272; fax: +966-12-695-2538) \\ ${ }^{6}$ University of California San Diego, 9500 Gilman Drive, La Jolla, CA, USA \\ ${ }^{7}$ Department of Genetics, Ain Shams University, Cairo, Egypt \\ ${ }^{8}$ Princess Al Jawhara Albrahim Centre of Excellence in Research of Hereditary Disorders \\ (PACER-HD), King Abdulaziz University, Jeddah, Saudi Arabia \\ (phone/fax: +966-2-460-0000) \\ *Corresponding author \\ e-mail: halatwi@ut.edu.sa; phone: +966-53-938-0024; fax:+966-2-460-0000
}

(Received 27 $7^{\text {th }}$ Mar 2020; accepted $7^{\text {th }}$ Jul 2020)

\begin{abstract}
Tumor necrosis factors (TNF- $\alpha$ ) are pro-inflammatory cytokines centrally involved in autoimmunity. Monoclonal antibodies against TNF- $\alpha$ are used to treat several autoimmune diseases including inflammatory bowel disease (IBD). The proportion of patients who experience primary nonresponse (PNR) to anti-TNF treatment is approximately $13-40 \%$. Secondary loss of response (LOR) to anti-TNF agents happens in $23-46 \%$ of IBD patients leading to a drug discontinuation rate of 5-13\%. A combination of factors including disease characteristics (e.g., phenotype, location, and severity), drug response (e.g., pharmacokinetics, pharmacodynamics, or immunogenicity), and treatment strategy (e.g., dosing regimen) has been associated with PNR and LOR. Therapeutic drug monitoring (TDM) relies on the measurement of serum concentrations of anti-TNF agents and anti-drug antibodies. TDM can be utilized to identify PNR and LOR and to assist clinicians in their decision-making. Additionally, TDM is used to optimize drug therapy (e.g., dose escalation) for patients who exhibit LOR. Recently, gut microbiota was believed to play a central role in immune regulation, and influence response to TNF- $\alpha$ antagonists. Microbial diversity for certain taxa can become a prognosis factor to monitor the response to treatment. In this article, we aim to review PNR and LOR, and discuss microbiota profiles associated with their occurrence.
\end{abstract}


Keywords: secondary loss of response, tumor necrosis factors (TNF)- $\alpha$, therapeutic drug monitoring, ulcerative coliti, Crohn's disease, infliximab, adalimumab, pharmacokinetic and pharmacodynami failure

Abbreviations: TNF: tumor necrosis factors, IBD: inflammatory bowel disease, PNR: Primary nonresponse, LOR: secondary loss of response, TDM: therapeutic drug monitoring, UC: ulcerative colitis, CD: Crohn's disease, IFX: Infliximab, ADL: Adalimumab, CZP: Certolizumab, GOL: Golimumab, CRP: Creactive protein, ADAs: antidrug antibodies, AZA: Azathioprine, SCFAs: short-chain fatty acids, SpA: spondyloarthritis, NSAID: nonsteroidal anti-inflammatory drugs

\section{Background}

Tumor necrosis factors (TNF- $\alpha$ ) are pro-inflammatory cytokines produced by certain cell types, such as T-cells and macrophages (Ebert et al., 2008). The number of these cells is increased in the intestinal mucosa of patients with inflammatory bowel disease (IBD). Accordingly, these cells are used as therapeutic targets. TNF- $\alpha$ functions as a component of the intestinal mucosa-mediated defensive line against mucosal pathogens and destructive inflammation (Allendoerfer and Deepe, 1998). TNF- $\alpha$ antagonists are monoclonal antibody drugs that are considered a revolutionary treatment for IBD. It has been demonstrated that TNF- $\alpha$ antagonists contribute to improving life quality of IBD patients and limit the requirement for surgeries and hospitalizations (Wang et al., 2019). Treatment guidelines encourage early utilization of TNF- $\alpha$ antagonists for IBD patients, particularly for patients who are refractory to other classes of medications and have been found to exhibit high-risk features at baseline (Gomollón et al., 2016). TNF- $\alpha$ antagonists are approved for the induction and maintenance of remission for both types of IBD, e.g., ulcerative colitis (UC) and Crohn's disease (CD) (Ha et al., 2012).

In cases of moderate-to-severe $\mathrm{CD}$, intensive treatment regimens incorporating TNF$\alpha$ antagonists, such as infliximab (IFX), adalimumab (ADL) and certolizumab (CZP) have been proven to be effective and can lead to clinical remission and mucosal healing (Hazlewood et al., 2015). IFX, ADL and GOL (golimumab) have been approved for the induction and maintenance of remission in UC. Despite this, the use of TNF- $\alpha$ antagonists is limited due to the cost and possibility of unpredictable side-effects, including infusion reactions, infections and lymphoma (Singh et al., 2011; Ben-Horin and Chowers, 2011). A small percentage $(5 \%)$ of IBD patients has been recorded to experience adverse drug reactions with severity ranging from simple skin rashes to anaphylactic reactions. It has been estimated that $10-30 \%$ of patients treated with TNF- $\alpha$ antagonists may not respond, and these patients are referred to as primary non-responders (PNRs). Additionally, 23$46 \%$ of patients may experience loss of response (LOR) over time, and this situation is accordingly referred to as secondary LOR (Roda et al., 2016). While LOR is mainly attributed to pharmacokinetic derangements, the precise etiologies underlying PNR are unknown (Ebert et al., 2008; Ben-Horin and Chowers, 2011; Billioud et al., 2011). The gut microbiota is recently thought to play a central role in immune regulation, and the accumulating literature on this process suggests that it also influences response to TNF$\alpha$ antagonists (Zhang et al., 2015; Rajca et al., 2014).

Mechanisms underlying PNR can be attributed to pharmacokinetic failure (Rocha et al.), pharmacodynamic failure (Ainsworth et al., 2008) and immunogenicity failure (Rojas et al., 2005). The causes of PNR to anti-TNF therapy are unknown, however, the possible factors contributing to PNR can be classified into four categories, patient-related factors, microbiome-related factors, disease-related factors and treatment-related factors (Ding et al., 2016). PNR can be often managed through optimization of dosing regimen (Hanauer et al., 2002) and combination therapy (Colombel et al., 2010; Coutinho et al., 
1995). Therapeutic drug monitoring (TDM) play a fundamental role to determine the appropriate assessment time for PNR occurs which at weeks 12 to 14 following induction (Papamichael et al., 2014; Cornillie et al., 2014). The human gut contains more than 100 trillion different microbial organisms, including more than 1000 species of bacteria, viruses, fungi and protozoa, collectively referred to as the microbiome (Honda and Littman, 2012). Four phyla are predominant and represent more than $99 \%$ of intestinal bacteria, which are Firmicutes, Bacteroidetes, Proteobacteria, and Actinobacteria (Eckburg et al., 2005; Ley et al., 2008). The Firmicutes and Bacteroidetes phyla represent the main commensal microbiota in healthy subjects, while Proteobacteria and Actinobacteria are significantly higher in IBD patientsqw (Sheehan et al., 2015; Andoh, 2016). Fecal microbiota transplantation (FMT) aims to recover the gut microbial level in patients via transferring fecal suspension from a healthy donor (Wang et al., 2017). In this article, we aim to explore PNR and LOR with a focus on the underlying causes of PNR and the possible involvement of gut microbiota.

\section{Primary non-response (PNR) definition}

A precise definition of PNR has not been determined, however, the accepted definition of PNR in connection with the use of anti-TNF- $\alpha$ drugs is failure to achieve clinical remission following the induction therapy period (Sprakes et al., 2012). It has been demonstrated that anti-TNF antagonists such as CZP, ADL and IFX are efficient for eliciting prompt remission and to prevent relapse in IBD. Despite the known efficacy of these drugs, it is recommended that clinicians estimate the improvement in the clinical signs after 8,12 and 14 weeks, respectively, following the initial infusions/injections with these drugs in PNR patients (Hanauer et al., 2002; Sands et al., 2004). Data from clinical trials and clinical practice differ in regard to the incidence of PNR, which ranges from 10 to $30 \%$ (Sprakes et al., 2012; Hanauer et al., 2002; Ford et al., 2011).

Several factors may contribute to the risk of PNR, including a disease duration of longer than 2 years, small bowel involvement, smoking, elevated C-reactive protein (CRP) and genetic mutations in apoptosis-related genes, such as FAS-L and caspase-9 (Ben-Horin et al., 2014). PNR can be minimized by optimization of the initially selected dosing regimens, by increasing the dose or reducing the intervals between doses, and by combining TNF- $\alpha$ antagonists with immunosuppressants, such as thiopurines or methotrexate (Table 1) (Ding et al., 2016; Roda et al., 2016). The latter approach is supported by data from several clinical trials. PNR is typically managed by switching to a different type of TNF- $\alpha$ antagonist that could be beneficial. However, several studies have demonstrated that the treatment outcome following a switch to a second anti-TNF antagonist in PNR patients is still poor with a response rate of approximately 50-65\% (Allez et al., 2010). Switching to an out-of-class medication that acts through different mechanisms may provide a worthwhile resolution to this problem (Sands et al., 2014). The proportion of PNR can differ among clinical trials (36-40\%) and according to clinical practice (13-33\%) (Ford et al., 2011). 
Table 1. A comparison between primary non-response (PNR) and secondary loss of response (LOR) (Ding et al., 2016; Roda et al., 2016)

\begin{tabular}{|c|c|c|}
\hline & $\begin{array}{l}\text { Primary non-response } \\
\text { (PNR) }\end{array}$ & $\begin{array}{c}\text { Secondary loss of response } \\
\text { (LOR) }\end{array}$ \\
\hline Definition & $\begin{array}{l}\text { Remission does not occur during the } \\
\text { induction of therapy period and clinical } \\
\text { signs and symptoms are continuous } \\
\text { (no healing) }\end{array}$ & $\begin{array}{l}\text { The patients who respond to the initial } \\
\text { induction of therapy but subsequently } \\
\text { suffer from clinical relapse and lack of } \\
\text { remission albeit maintenance of therapy }\end{array}$ \\
\hline $\begin{array}{l}\text { Percentage of } \\
\text { those who do not } \\
\text { respond }\end{array}$ & $10-30 \%$ & $23-46 \%$ \\
\hline Incidence & $\begin{array}{l}\text { Differs between clinical trial and clinical } \\
\text { practice from } 10-20 \% \text { to } 13-30 \%\end{array}$ & $\begin{array}{l}\text { Its incidence is } 13 \% \text { for Infliximab (IFX) } \\
\text { and } 24 \% \text { for Adalimumab (ADA) }\end{array}$ \\
\hline Risk factors & $\begin{array}{l}\text { - Disease longer than } 2 \text { years } \\
\text { - Small bowel involvement } \\
\text { - Smoking } \\
\text { - C reactive protein } \\
\text { - Genetic mutations such as FAS-L and } \\
\text { caspase-9 in the apoptosis related genes }\end{array}$ & $\begin{array}{l}\text { - Formation of antibodies against TNF } \alpha \\
\text { antagonists (immunogenicity) } \\
\text { - Use of episodic TNF } \alpha \text { antagonists in 5- } \\
13 \% \text { of patients }\end{array}$ \\
\hline Management & $\begin{array}{l}\text { - Optimization of the dosing regimen } \\
\text { - Combination therapy }\end{array}$ & $\begin{array}{l}\text { Use of concomitant immunomodulators } \\
\text { with Anti -TNF } \alpha \text { antagonists }\end{array}$ \\
\hline $\begin{array}{l}\text { Therapeutic } \\
\text { options }\end{array}$ & $\begin{array}{l}\text { - Switching to another anti- TNF could be } \\
\text { beneficial } \\
\text { - Switch out of the therapeutic groups that } \\
\text { are characterized by other working } \\
\text { mechanisms }\end{array}$ & $\begin{array}{l}\text { - Change to another TNF } \alpha \text { antagonist agent } \\
\text { was associated with a complete or partial } \\
\text { response in } 92 \% \text { of patients } \\
\text { - Switching within a therapeutic class to } \\
\text { another anti-TNF agent may restore } \\
\text { clinical response }\end{array}$ \\
\hline Strategy & $\begin{array}{l}\text { - Dose escalation based on the } \\
\text { pharmacokinetic } \\
\text { - Therapeutic drug monitoring (TDM) }\end{array}$ & Therapeutic drug monitoring (TDM) \\
\hline
\end{tabular}

\section{Proposed mechanisms underlying PNR}

Three mechanisms that could explain PNR to TNF- $\alpha$ antagonists are presented in Figure 1.

\section{Pharmacokinetic failure}

This phenomenon occurs when suboptimal levels of TNF- $\alpha$ antagonists circulate either because of suboptimal dosing or interaction with anti-drug antibodies (Rocha et al.) that leads to accelerated drug clearance (non-immune) via tissues or through the systemic circulation. The three fundamental mechanisms implicated in pharmacokinetic failure include:

i. Proteolytic catabolism that occurs in the reticuloendothelial system due to the ability of monoclonal antibodies to bind to $\mathrm{Fc}$ gamma receptors ( $\mathrm{Fc}$, or Fragment/crystallizable, is a surface protein, and the term is derived from the proteins' specificity to bind a part of an antibody known as the Fc region.

ii. Degradation that occurs in lysosomes as a result of interaction with membranebound TNF (Keizer et al., 2010; Ordás et al., 2012). 
iii. Ulcerated mucosa that leads to clearance and drug loss through the mucosal membrane as a result of non-immune clearance, ultimately resulting in considerable loss of protein and electrolytes in addition to loss of drug (Brandse et al., 2015).

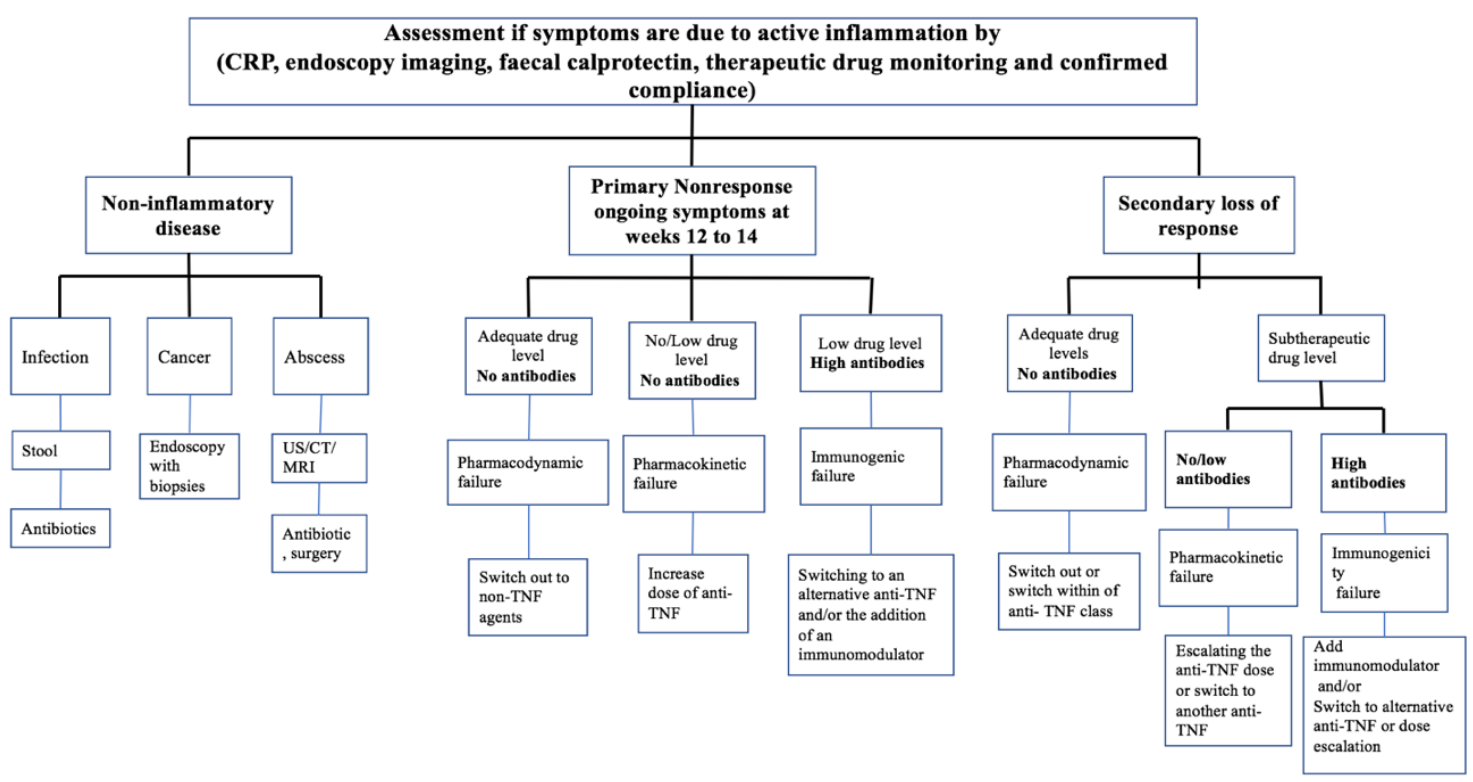

Figure 1. Management of primary nonresponse and secondary loss of response. Taken from (Ding et al., 2016; Roda et al., 2016)

\section{Pharmacodynamic failure}

This type of failure occurs when no improvement in clinical symptoms occurs despite the presence of adequate circulating drug and absence of Antidrug antibodies (ADAs) (Ainsworth et al., 2008). The most favorable alternative avenue would be to switch to an out-of-class medication, such as a leukocyte trafficking inhibitor or an anti-cytokine (Ding et al., 2016).

\section{Immunogenicity failure}

This scenario is characterized by a lack of improvement in symptoms in the presence of low circulating serum TNF- $\alpha$ antagonists and high levels of ADAs. One of the strongest factors linked to non-response is the formation of ADAs against anti-TNF $\alpha$ antagonists. Antibodies possess the ability to interfere with TNF receptors and to accelerate the clearance of the drug through the reticuloendothelial system. Low levels of ADAs have been implicated in effectively achieving remission (Rojas et al., 2005). Neutralizing and non-neutralizing antibodies and low drug concentrations have been reported in up to $83 \%$ of PNRs (Echarri et al., 2014). Additionally, the effective induction of remission in PNRs by using a second TNF- $\alpha$ antagonist occurs in only $50 \%$ of IBD patients (Gisbert et al., 2015). The perfect option is to switch to an alternative anti-TNF or to incorporate the use of an immunomodulator. Following a drug switch, therapeutic drug monitoring should be repeated to determine if antibody disappearance has occurred (Ding et al., 2016). 


\section{Potential causes of PNR to anti-TNF therapy}

The causes of PNR to anti-TNF therapy are unknown; however, the possible factors contributing to PNR can be classified into four categories (see Fig. 2).

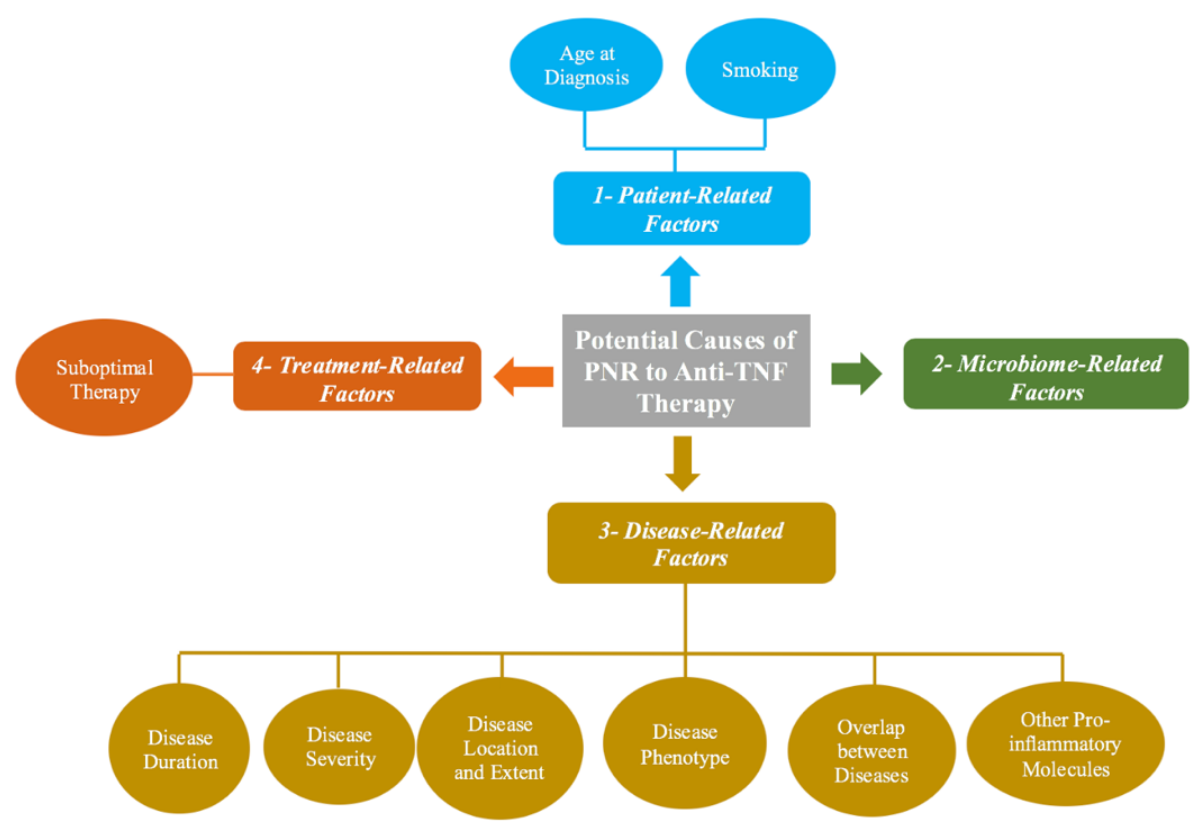

Figure 2. Potential causes of PNR to anti-TNF therapy

\section{Patient-related factors}

Factors like gender, lack of concomitant immunosuppression, age, prolonged duration of disease, smoking, CD phenotype, and disease not limited to the colon may contribute to the response to anti-TNF $\alpha$ agents (Danese et al., 2011). The two most patient-related factors include:

\section{Age at diagnosis}

The connection between age at the time of diagnosis and PNR is controversial (Juillerat et al., 2014), although diagnosis at an early age (less than 17 years) is often associated with poor outcome (Grover et al., 2014). Interestingly, younger patients tend to respond better to anti-TNF therapy in comparison with older patients (Vermeire et al., 2002).

\section{Smoking}

Smoking is an environmental factor that likely plays a role in reducing patient responsiveness to anti-TNF agents. A relationship between smoking and PNR has been previously reported. Approximately $30 \%$ of patients who are smokers are non-responsive to IFX at week 4 (Arnott et al., 2003). Smoking has been found to decrease the influence of anti-TNF drugs and to increase the likelihood of non-response (Cohen et al., 2011; Chaparro et al., 2011). According to a study performed on 221 ADL-treated patients, 
$21.2 \%$ of the patients were smoking at the time of induction (OR 0.52, $\mathrm{P}=0.049)$ (Ding et al., 2016; Kiss et al., 2011). Additionally, PRECISE-3 data indicated that smokers had more active disease compared to non-smokers (HR: 1.404; 95\% CI: 1.09-1.77; P = 0.007) (Sandborn et al., 2015).

\section{Microbiome-related factors}

The exact role of the gut microbiota in PNR is not well understood. Several studies have observed no significant difference in the gut microbiota composition before and after treatment with TNF-antagonists (Zhang et al., 2015). In contrast, results published by Bazin et al. (2018) indicated that gut microbial composition could be used as a biomarker that is predictive of clinical response to anti-TNF treatments. Additionally, microbial diversity in the presence or absence of particular taxa has been used as a prognostic factor to monitor the response to treatment or the presence of several diseases, including colorectal cancer (Gagnière et al., 2016; Bazin et al., 2018). It has been found that in some diseases, such as melanoma, particular microbiota species, can be used as biomarkers to determine the correlation between the colitis and resistance to immunotherapy (Dubin et al., 2016).

Recent study compared the microbial composition among anti-TNF therapy-treated UC patients; responders showed increase of the concentrations of Faecalibacterium prausnitzii and decrease of the rate of dysbiosis compared with non-responders. Furthermore, both responders and non-responders had a featured mucosal antimicrobial peptides expression patterns (Magnusson et al., 2016). In addition, another recent study showed that in the case of discontinuation of using anti-TNF- $\alpha$ treatment, low abundance of $F$. prausnitzii can be used as a biomarker to predict the early incidence of Crohn's disease (Rajca et al., 2014). In rheumatology, dysbiosis in the oral and gut microbiota of rheumatoid arthritis patients had been monitored. This dysbiosis can be partly treated by using disease-modifying antirheumatic drugs (DMARD) (Zhang et al., 2015). However, the influence of rheumatoid arthritis was moderate on the gut microbiota compared to the oral microbiota. Moreover, decrease of risk factor and low concentration of Holdemania filiformis and Bacteroides species have been observed in the responder patients after therapy (Zhang et al., 2015).

\section{Disease-related factors}

A range of disease-related factors has been associated with PNR. They are the following:

\section{Disease duration}

According to several studies, patients with shorter disease durations ( $<2$ years) exhibit better responses and higher long-term remission rates compared to those of patients who have had the disease for more than 2 years. For instance, the Crohn's Trial of the Fully Human Antibody Adalimumab for Remission Maintenance (CHARM) study was performed to determine the rates of response and remission to ADL. Assessments were performed at week 26 to evaluate the impact of disease duration on response and remission rates. More patients with a short disease duration experienced response compared to patients with a disease duration of $>2$ years or $>5$ years $(56 \%$, $35 \%$ and $37 \%$, respectively) (Colombel et al., 2007). Similar results were observed in the PRECISE 2 study that evaluated remission and response to certolizumab pegol (CZP) in CD at week 26. Of the CD patients treated with CZP, 62\% exhibited PNR 
$(p=0.02)$ (Schreiber et al., 2010). Additionally, greater rates of response and remission were observed in CD patients with disease duration of $<2$ years compared to those of patients with disease duration of $\geq 5$ years (Reinisch et al., 2009; Colombel et al., 2015).

\section{Disease severity}

Several studies suggest that disease severity is one of the main factors that contribute to non-response (Castro-Laria et al., 2016; Reinisch et al., 2011). The efficacy of antiTNF treatment has been observed to be lower in severely inflamed tissue. This is likely due to hastening of non-immune drug clearance (Fasanmade et al., 2009, 2011). PNR could also be attributed to the use of inadequate induction dosages. It has been proposed that fecal loss of anti-TNF drugs via ulcerated, denuded mucosa contributes to PNR (Brandse et al., 2015).

\section{Disease location and extent}

Although some studies suggest the presence of a correlation between localized ileal stricture disease and PNR, much of the data regarding this correlation remains conflicting (Louis et al., 2007). One study proposed ileal resection as an effective treatment for localized ileal stricture disease, but a separate study suggested that the localization of disease did not directly affect the response rate. The study compared two categories of patients who were treated with anti-TNF therapy, e.g., patients with isolated ileal stricture disease and patients with stricture disease at an unspecified location. The results indicated that both patient categories required surgery at the same rate (Moran et al., 2014).

\section{Disease phenotype}

An association between disease phenotype and response to anti-TNF therapies has been suggested in several studies. In Kiss et al. (Kiss et al., 2011; Ding et al., 2016), which included $201 \mathrm{CD}$ patients treated with ADL, at week 52, PNR with continued clinical remission had been observed in patients who have active luminal disease (OR: 3.89; $95 \%$ CI: $1.43-10.6 ; \mathrm{P}=0.008$ ). Moreover, at week 12, it had been noticed that the presence of two pathological phenotypes, luminal and fistulizing in CD patients led to decrease of remission rates. Otherwise, this rate was sort of high in CD patients with only luminal phenotype $(42.5 \%$ vs. $56.3 \%, \mathrm{P}=0.06)$.

\section{Overlap between diseases}

An overlap between inflammatory diseases such as Spondylarthritis (SpA) and IBD is possible. For instance, 5-10\% of SpA patients may have concomitant IBD, while up to $30 \%$ of IBD patients may also experience inflammatory arthritis (Bazin et al., 2018). Additionally, $60 \%$ of SpA patients have microscopic gut inflammation (Lin et al., 2014; Van Praet et al., 2012). These overlaps may often explain resistance to treatment with TNF antagonists.

\section{Other pro-inflammatory molecules}

Theoretically, IBD patients characterized as PNR may not benefit from switching between IFX and ADL since both drugs possess the same chemical structure and function (Dassopoulos, 2005). Accordingly, a lack of response to anti-TNF agents could be due to specific disease characteristics, with dose intensification would not achieve the required 
result. A potential explanation for this is that pro-inflammatory molecules other than TNF- $\alpha$ may be responsible for the pathogenesis of the disease (Gisbert et al., 2015).

\section{Treatment-related factors}

A range of treatment-related factors is associated with PNR. They are the following:

\section{Suboptimal therapy}

The common indicators of suboptimal therapy are dose escalation of anti-TNF and discontinuation of treatment. Among the anti-TNF patients, $25.8 \%$ of UC patients required dose-escalation and $19.2 \%$ of $\mathrm{CD}$ patients required increased doses. The underlying reason for these therapeutic alterations is the worsening of clinical signs and symptoms (94.2\% UC and $94.5 \% \mathrm{CD}$ ). Among UC patients, the cause of discontinued initial anti-TNF therapy was the appearance of negative clinical symptoms $(45.6 \%)$ or the occurrence of an adverse reaction (23.2\%). Additionally, $49.5 \%$ of discontinued UC patients were switched to an alternate anti-TNF therapy. Among CD patients, the cause of discontinued initial anti-TNF therapy was uncontrolled symptoms (36.3\%) or an adverse reaction (27.4\%). Additionally, $62.7 \%$ of discontinued CD patients were switched to another anti-TNF therapy (Lindsay et al., 2017).

\section{Rescue therapeutic strategies in cases of PNR}

PNR is often managed through the following two strategies:

\section{Optimization of dosing regimen}

Data derived from CLASSIC 1 (Clinical Assessment of Adalimumab Safety and Efficacy Studied as Induction Therapy in Crohn's Disease) demonstrated that a higher dosage of ADL could achieve better remission rates at week 4 of treatment compared to that of lower dosages. Similarly, data from the PRECISE-2 (Pegylated Antibody Fragment Evaluation in Crohn's Disease: Safety and Efficacy) and ACCENT-1 (A Crohn's Disease Clinical Trial Evaluating Infliximab in a New Long-Term Treatment Regimen) trials demonstrated that higher dosages of CZP and IFX during the induction period are associated with a lower risk of PNR (Hanauer et al., 2002).

\section{Combination therapy}

Results obtained from the SONIC (Study of Biologic and Immunomodulator Naïve Patients in Crohn's disease) suggested that AZA (Azathioprine) exerts an additive influence on mucosal healing at week 26 when combined with IFX. Accordingly, combining antiTNF drugs with immunosuppressive therapy appears to enhance drug efficacy and can theoretically help to prevent PNR (Colombel et al., 2010; Coutinho et al., 1995).

\section{The role of therapeutic drug monitoring (TDM) in PNR}

The appropriate assessment time for PNR occurs at weeks 12 to 14 following induction therapy (Papamichael et al., 2014; Cornillie et al., 2014). In week 4, $5 \mathrm{mg} / \mathrm{mL}$ serum concentration of adalimumab was used as an indicator to identify the risk of antibody formation. In a study on adalimumab-treated CD patients $(n=168)$, mucosal healing is 
associated with a trough level, and this can be utilized to predict clinical response. The median concentrations of ADL in serum were $8.6 \mathrm{lg} / \mathrm{mL}$ (interquartile range (IQR): $6.5-$ 10.8 ) at week 2 and $5.3 \mathrm{lg} / \mathrm{mL}$ (IQR, 2.8-10.9) at week 4. At week 4, a comparison was performed between two types of patients, including those who received $80 / 40 \mathrm{mg}$ and those who received 160/80 $\mathrm{mg}$ as a loading dose. The second patient group exhibited higher adalimumab serum concentrations (3.6 vs. $11.6 \mathrm{lg} / \mathrm{mL} ; \mathrm{P}<0.0001)$ and possessed a lower incidence of PRN "as needed" (odds ratio [OR]: 0.02; 95\% CI: 0.003-0.2; $\mathrm{P}<0.0001$ ) (Karmiris et al., 2009; Ding et al., 2016). A serum trough concentration of < 5 $\mathrm{mg} / \mathrm{mL}$ has been associated with an increased future risk of the formation of antibodies specific to ADL (HR: 25.12; 95\% CI: 5.64-111.91; P = 0.0002) (Baert et al., 2016).

A prospective study that examined serum drug concentrations of $32 \mathrm{CD}$ patients treated with IFX $(n=15)$ and ADL $(n=17)$ at week 14 demonstrated that responders possessed a higher trough concentration than that of non-responders (FX [5.60 $\mathrm{lg} / \mathrm{mL}]$. ADL was compared to non-responders using the Harvey-Bradshaw Index, C-reactive protein (CRP) or fecal calprotectin concentration [IFX $0.032 \mathrm{lg} / \mathrm{mL}$ and ADL $2.62 \mathrm{lg} / \mathrm{mL}$; $P=0.01]$ ) (Echarri et al., 2014). At week 6, high trough concentrations of IFX (> $3 \mathrm{lg} / \mathrm{mL}$ ) and $\mathrm{ADL}(>4.5 \mathrm{lg} / \mathrm{mL})$ were used, and $>90 \%$ remission and response rates were achieved. Additionally, sustained anti-drug antibody levels were observed in $26 \%$ of the IFX-treated patients and in $0 \%$ of the ADL-treated patients. In general, it has been suggested that the observation of adequate anti-TNF concentrations at weeks 4 to 6 is highly predictive of response to anti-TNF therapy. At week 14, a low anti-TNF drug concentration and the occurrence of antibody formation can predict primary non-response (Ding et al., 2016).

\section{Proactive and reactive therapeutic drug monitoring}

Proactive TDM is applied during remission. The aim of this approach is to modify the dose of IFX depending on individual pharmacokinetics and pharmacodynamics to avoid sub-therapeutic dosing and the risk of failure or to minimize the intensity of the therapy to reduce the financial costs associated with supra-therapeutic dosing. In contrast, reactive TDM is applied as a result of treatment failure despite the previous use of IFX therapy to achieve a successful outcome. This approach depends on pharmacokinetics and pharmacodynamic in response to IFX intensification, change to another TNF inhibitor, or the use of a new biologic drug class (Steenholdt, 2018).

Recent data suggest that proactive TDM of IFX leads to successful therapeutic outcomes in IBD. Despite this, the clinical benefits of proactive infliximab have not been confirmed after first reactive testing. A retrospective cohort study was carried out from September 2006 to January 2015 on IBD patients who underwent to maintenance IFX treatment and received an initial reactive testing (Papamichael et al., 2018). The purpose of this study was to compare outcomes at long-term between proactive infliximab monitoring after reactive testing and just reactive testing in IBD patients. Patients were divided into two groups; Group A represented a proactive infliximab monitoring after reactive testing while Group B represented a reactive testing alone. Treatment failure was defined as drug discontinuation due to either LOR or the occurrence of a serious adverse event. The total number of IBD patients was $102(n=70,69 \%$ with CD; Group A, $n=33$ and Group B, $\mathrm{n}=69$ ) were followed for a median of 2.7 years (interquartile range [IQR], 1.4-3.8 years). Multiple Cox regression analysis determined that patients who had proactive following reactive TDM were independently associated with less treatment 
failure (hazard ratio [HR] $0.15 ; 95 \%$ confidence interval $[\mathrm{CI}] 0.05-0.51 ; \mathrm{P}=0.002$ ) and fewer IBD-related hospitalizations [HR: 0.18; 95\% CI 0.05-0.99; P $=0.007]$. Conclusion of this study was the proactive infliximab monitoring following reactive testing led to better drug stability and decrease of hospitalizations among IBD patients compared to reactive testing alone (Papamichael et al., 2018).

A multicenter retrospective cohort study was performed from June 2006 until December 2015 on IBD patients who underwent to maintenance adalimumab therapy (Papamichael et al., 2019). The study aimed to evaluate long-term the outcomes between IBD patients who had at least one proactive TDM of ADL with standard of care and/or reactive TDM. Treatment failure was defined as drug discontinuation due to secondary LOR, the occurrence of a serious adverse event, or the need for IBD-related surgery. The total number of IBD patients was 382 (Crohn's disease, $n=311,81 \%$ ) received at least one proactive TDM $(n=53)$ or the standard of care (empirical dose escalation, $n=279$; reactive TDM, $n=50$ ). Patients were followed for a median of 3.1 years (interquartile range, 1.4-4.8 years). Multiple Cox regression analyses demonstrated that obtaining at least one proactive TDM led to decrease the risk of treatment failure (hazard ratio [HR]: $0.4 ; 95 \%$ confidence interval $[\mathrm{CI}]: 0.2-0.9 ; \mathrm{p}=0.022)$. The study provided the foremost evidence that reducing of risk of treatment failure may be attributed to proactive TDM of ADL compared with standard of care (Papamichael et al., 2019).

\section{Microbiota profiles and primary non-response to anti-TNF agents}

The human gut has more than 100 trillion various microbial organisms, including more than 1000 species of bacteria, viruses, fungi and protozoa, collectively referred to as the microbiome (Honda and Littman, 2012). Four phyla are predominant and represent more than $99 \%$ of intestinal bacteria, which are Firmicutes, Bacteroidetes, Proteobacteria, and Actinobacteria (Eckburg et al., 2005; Ley et al., 2008). The Firmicutes and Bacteroidetes phyla represent the main commensal microbiota in healthy subjects, while Proteobacteria and Actinobacteria are significantly higher in IBD patients (Figs. 3 and 4; Sheehan et al., 2015; Andoh, 2016).

\section{Functional composition of gut microbiota in IBD patients}

Taxa of Faecalibacterium, Odoribacter, Leuconostocaceae, Phascolarctobacterium and Roseburia provide short-chain fatty acids (SCFAs) through a process that involves the fermentation of undigested carbohydrates. SCFAs are responsible for the regulation of trans-epithelial transport, colonocyte proliferation and differentiation, mucosal inflammation, intestinal motility, and barrier function (Smith et al., 2013; Peng et al., 2009). The concentration of SCFAs is significantly reduced in IBD patients, and this is likely a result of a decrease in the bacteria that produce them. Bifidobacterium synthesizes vitamins such as vitamin $\mathrm{K}$ and the water-soluble B vitamins (LeBlanc et al., 2011). At the functional metagenomic level, amino acid synthesis required for the production of these vitamins is decreased and amino acid transporter genes are increased due to an increase in auxotrophic and pathobiont bacteria (Ahuja, 2015). Increased glutathione and riboflavin metabolism and increased toxin secretion are associated with an increase in sulphate-reducing bacteria, such as Desulfovibrio (Ahuja, 2015; Erickson et al., 2012). 


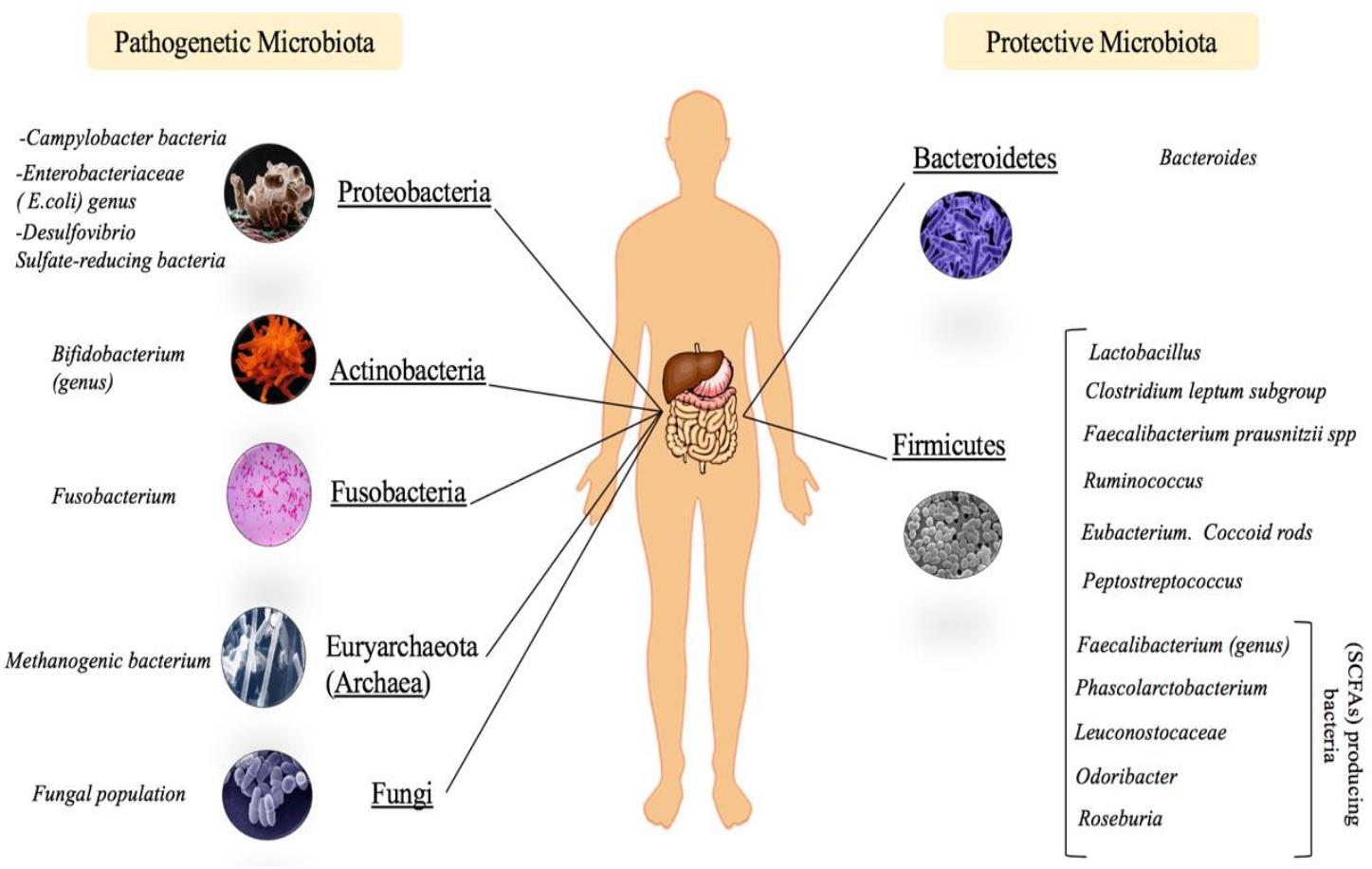

Figure 3. Composition of gut microbiota (pathogenic and protective)

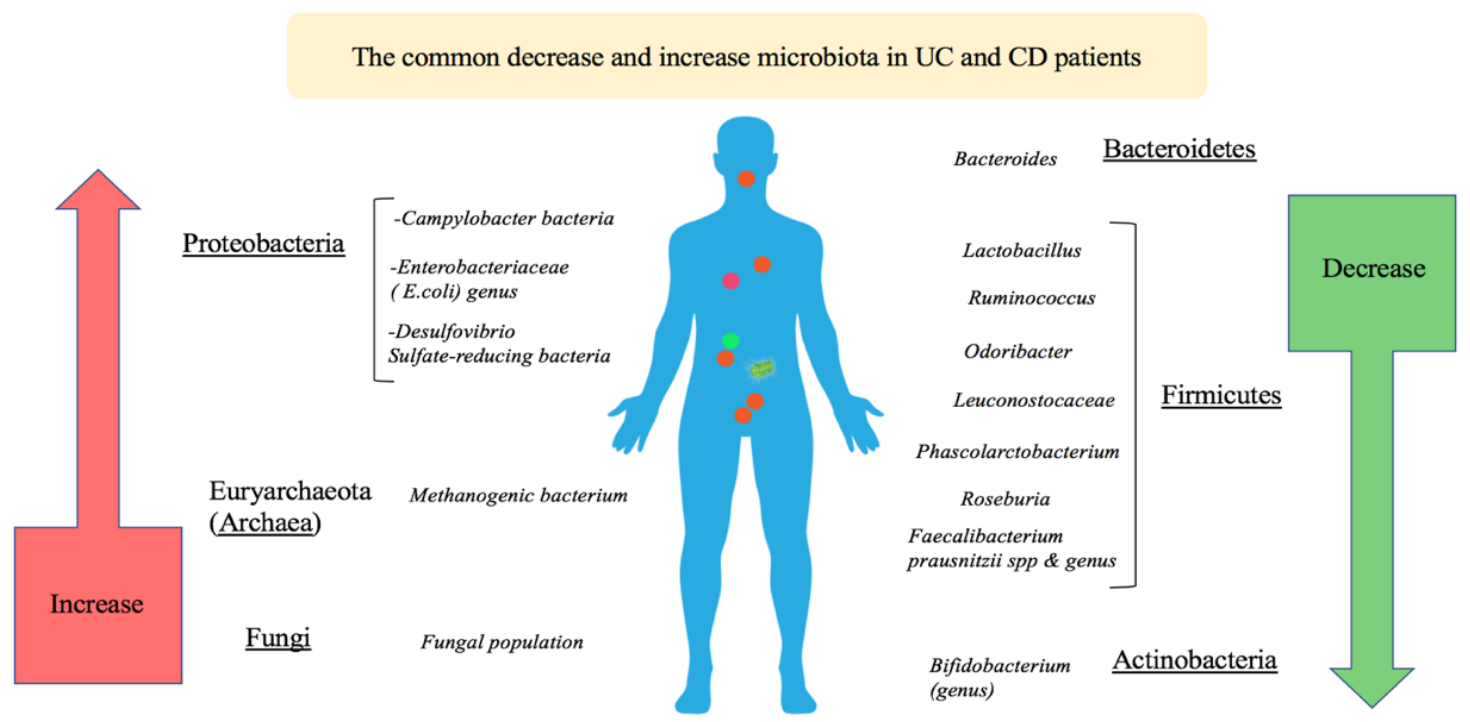

Figure 4. The common decrease and increase of microbiota in UC and CD patients

The clinical response to therapy is highly dependent upon the quantity and quality of bacterial taxa and upon any changes in bacterial taxa that occur in response to treatment. Accordingly, patients with few changes in their taxa in response to treatment typically exhibit improved drug responses. In contrast, patients who exhibit drastic changes in many bacterial taxa following treatment are believed to exhibit poorer drug responses. This hypothesis suggests that patients possessing an unstable gut microbial composition 
may possess a higher risk for anti-TNF- $\alpha$ treatment failure (Bazin et al., 2018). Additionally, TNF- $\alpha$ inhibitors may affect the composition of the gut microbiota, either directly or indirectly. TNF- $\alpha$ inhibitors are characterized by their ability to cure and downregulate inflammation in the infected gastrointestinal tract mucosa. These drugs also seek to repair wounded digestive epithelium and rebalance the composition of mucosal microbiota. These functions of TNF- $\alpha$ inhibitors may indirectly affect the microbiota composition of the gut (Baert et al., 1999).

Bazin et al. (2018) demonstrated that the gut microbial composition could be used as a predictive biomarker for clinical response to anti-TNF. Interestingly, such a predictive characteristic of anti-TNF inhibitors has been confirmed in several studies examining a number of different diseases. Additionally, microbial diversity in the presence or absence of particular taxa has been used as a prognostic factor to monitor diseases such as colorectal cancer or response to treatment (Bazin et al., 2018). For instance, an increase in the quantity of cyclomodulin-producing E. coli, enterotoxigenic Bacteroides fragilis, and Fusobacterium nucleatum was observed in cases of advanced colorectal cancer (Gagnière et al., 2016). Similarly, alteration in the microbiota composition has been used to explain resistance to immunotherapy in melanomas. It has also been postulated that some microbiota species possess the capacity to modify and improve the effects of therapy (Dubin et al., 2016; Routy et al., 2018).

A recent study demonstrated a decrease in dysbiosis and an increase in the quantity of Faecalibacterium prausnitzii exists in patients with UC who respond to anti-TNF therapy when compared to these factors in non-responders (Magnusson et al., 2016). Additionally, the results of this study demonstrated that responders and non-responders exhibit distinct expression patterns of mucosal antimicrobial peptides. Their findings also suggested that a relationship exists between decreased concentrations of $F$. prausnitzii and clinical relapse in CD patients treated with anti-TNF- $\alpha$ therapy (Rajca et al., 2014).

For the treatment of inflammatory diseases such as IBD and Spondyloarthritis (SpA), a therapeutic revolution occurred after the identification of tumor necrosis factor-alpha (TNF- $\alpha$ ) antagonists, and this was particularly true for patients who had previously failed to respond to NSAID and conventional DMARDs (Sedger and McDermott, 2014; Ward et al., 2016). A number of studies have demonstrated that changes in the composition of the gut and mouth microbiome occur following the onset of several diseases. Subsequently, altered gut and mouth microbiomes are again partially modified in response to treatment, and these alterations can potentially predict response to treatment (Zhang et al., 2015; Phillips, 2015).

The effect of treatment on the gut microbiome is considered moderate when compared to these effects on the oral microbiome. It has been suggested that a higher probability of response occurs in patients who possess a significant number of virulence factors prior to therapy (Phillips, 2015).

\section{Variations in the gut microbiota signature}

In 2015, Zhang et al. (2015) performed an experiment on rheumatoid arthritis patients. They reported that differences observed in the gut microbiota composition before and after non-biologic DMARDs treatment were not significant. Additionally, Busquets et al. (2015) demonstrated that treatment with a TNF- $\alpha$ inhibitor such as ADL can affect the gut microbial composition of CD patients via recovery of Firmicutes, Bacteroides, and Actinobacteria phyla and a decrease in E. coli during treatment. This result was not observed in the study by Bazin et al., which may be owing to the different patient 
population that was studied and the therapies that were used (Bazin et al., 2018). Coyte et al. (2015) reported that an unstable microbiota composition was observed in nonresponders over time. Considerable alteration in the microbiota composition has been linked to inflammatory diseases such as neurodevelopmental disorders and IBD, but it has not been associated with Spondyloarthritis. Magnusson et al. (2016) observed that UC patients who possess the capacity to respond to the induction of anti-TNF- $\alpha$ therapy exhibited a high abundance of $F$. prausnitzii compared to that of non-responder patients. A significant proportion of Lactobacillus delbrueckii has been previously observed in responder patients. These bacteria possess the ability to ferment kefir and are used as probiotics for IBD therapy (Rocha et al., 2014).

Several studies that were performed on humans have confirmed that the Bacteroidetes population is greater than that of Firmicutes in IBD patients compared to healthy controls (Wright et al., 2015). However, conflicting data were reported in a study by Rooks et al. (2014) compared mice that were treated with anti-TNF antibodies post colitis to mice that were treated with an antibiotic; Firmicutes populations were increased and the proportions of Bacteroidetes were decreased in the mice treated with anti-TNF antibodies. These contrasting results highlight the finding that microbial responses are different after anti-TNF treatment. Based on this, patient responses to anti-TNF treatment may also differ (Chiodini et al., 2013). Firmicutes is considered the most common phylum that is restored in CD patients treated with ADL. E. coli levels are also often increased in CD patients (Busquets et al., 2015). Bazin et al. also observed that the majority of nonresponders exhibited changes in the order Bacteroides quantity, where two patients exhibited a decrease in these bacteria and five patients exhibited an increase. Responders, however, did not exhibit any changes in the Bacteroides order. This illustrates that the proportion of the order Bacteroides differs significantly for IBD conditions. The relationship between microbiota composition clusters and clinical response has been demonstrated without the presumption of causality. Fecal microbiota signatures could be used to predict clinical response to anti-TNF- $\alpha$ therapy, particularly in the absence of reliable biomarkers (Bazin et al., 2018). A balanced diversity in the composition of symbiotic microbiota, such as bacteria, fungi, and viruses may be used to predict a positive outcome to treatment (Ciccia et al., 2016).

\section{Fecal microbiota transplantation}

Fecal microbiota transplantation (FMT) aims to recover the gut microbial level in patients via transferring fecal suspension from a healthy donor. FMT is associated with recurrent Clostridium difficile infection (CDI). CDI is an appropriate situation for FMT, as it refers to gastrointestinal dysbiosis with Clostridium difficile overgrowth (Cohen et al., 2010). A study cohort from Shanghai Children's Hospital, China, was used to investigate the influence of IFX on the composition and function of the fecal microbiota of $C D$ patients and healthy controls $(C D[n=11]$, healthy control $[n=16]$, all fecal samples [ $n=48]$, CD patient samples [ $n=32$ ], baseline $[n=8]$, various times during IFX therapy $[n=24]$, healthy individuals $[n=16])$. Prior to IFX therapy in pediatric CD patients, a lower biodiversity in fecal microbiome composition, an increase in Enterococcus, and a decrease in SCFA-producing bacteria including Anaerostipes, Blautia, Coprococcus, Faecalibacterium, Lachnospira, Odoribacter, Roseburia, Ruminococcus, and Sutterella, were observed. Additionally, alterations in metabolic functions of the gut microbes in CD patients were noted. In post-IFX samples, IFX treatment restored the gut microbiota to a normal state in pediatric $\mathrm{CD}$ patients, and the 
abundance of SCFA-producing bacteria (the genera Blautia, Faecalibacterium, Odoribacter, and Sutterella) was associated with sustained therapeutic response. The gut microbiota were also improved in terms of richness and diversity. During IFX treatment, levels of Enterococcaceae, Planococcaceae, and Streptococcaceae were reduced in pediatric CD patients. In contrast, Coprococcus, Lachnospira, Roseburia, and Ruminococcus levels were elevated in the CD patients after treatment with IFX; however, their increases were unstable (Wang et al., 2017).

A study that was performed on adult CD patients $(n=33)$ aimed to identify alterations in the gut microbiota after IFX withdrawal. In this study, Rajca et al. (2014) noticed that CD patients exhibiting long-term remission possessed higher concentrations of Firmicutes compared to that of the relapsed CD patients. Additionally, relapsed CD patients possessed low levels of $F$. prausnitzii and Bacteroides during the year prior to IFX withdrawal.

\section{Conclusion}

PNR and LOR are important challenges faced by clinicians who treat patients with IBD. Although the precise cause of PNR is not well characterized, the most acceptable reason for LOR to TNF antagonists is immunogenicity that leads to the development of ADAs, which ultimately neutralize the drug or hasten its clearance. Therapeutic drug monitoring (TDM) is useful for aiding appropriate therapeutic decisions in cases of treatment failure. Through the use of TDM, clinicians can choose among dose intensification, the addition of an immunomodulator, or switching between classes of drugs. Future research should focus on the underlying mechanisms responsible for the development of PNR and on strategies to overcome LOR. The exact role that the gut microbiota plays in the process of treatment failure remains poorly understood. Microbial diversity in the presence or absence of particular taxa can be used as a prognosis factor to monitor the response to treatment. Strongly recommended increasing the prospective clinical trials to study the modification of the gut microbiota composition and determine which microbe(s) are responsible for primary non-response or loss of response and thereby used as a biomarker predictive. Therefore, the modification of microbiota composition can be used to improve the research of probiotic by creating new medications based on the patient's microbiota composition (if possible).

\section{REFERENCES}

[1] Ahuja, V. (2015): Inventory of a reservoir: friends \& foes. - The Indian Journal of Medical Research 142: 4.

[2] Ainsworth, M. A., Bendtzen, K., Brynskov, J. (2008): Tumor necrosis factor-alpha binding capacity and anti-infliximab antibodies measured by fluid-phase radioimmunoassays as predictors of clinical efficacy of infliximab in Crohn's disease. - The American Journal of Gastroenterology 103: 944.

[3] Allendoerfer, R., Deepe, G. S. (1998): Blockade of endogenous TNF- $\alpha$ exacerbates primary and secondary pulmonary histoplasmosis by differential mechanisms. - The Journal of Immunology 160: 6072-6082.

[4] Allez, M., Karmiris, K., Louis, E., Van Assche, G., Ben-Horin, S., Klein, A., Van der Woude, J., Baert, F., Eliakim, R., Katsanos, K. (2010): Report of the ECCO pathogenesis workshop on anti-TNF therapy failures in inflammatory bowel diseases: definitions, frequency and pharmacological aspects. - Journal of Crohn's and Colitis 4: 355-366. 
[5] Andoh, A. (2016): Physiological role of gut microbiota for maintaining human health. Digestion 93: 176-181.

[6] Arnott, I., Mcneill, G., Satsangi, J. (2003): An analysis of factors influencing short-term and sustained response to infliximab treatment for Crohn's disease. - Alimentary Pharmacology \& Therapeutics 17: 1451-1457.

[7] Baert, F., Kondragunta, V., Lockton, S., Casteele, N. V., Hauenstein, S., Singh, S., Karmiris, K., Ferrante, M., Gils, A., Vermeire, S. (2016): Antibodies to adalimumab are associated with future inflammation in Crohn's patients receiving maintenance adalimumab therapy: a post hoc analysis of the Karmiris trial. - Gut 65: 1126-1131.

[8] Baert, F. J., D’haens, G. R., Peeters, M., Hiele, M. I., Schaible, T. F., Shealy, D., Geboes, K., Rutgeerts, P. J. (1999): Tumor necrosis factor $\alpha$ antibody (infliximab) therapy profoundly down-regulates the inflammation in Crohn's ileocolitis. - Gastroenterology 116: 22-28.

[9] Bazin, T., Hooks, K. B., Barnetche, T., Truchetet, M.-E., Enaud, R., Richez, C., Dougados, M., Hubert, C., Barré, A., Nikolski, M. (2018): Microbiota composition may predict antitnf alpha response in spondyloarthritis patients: an exploratory study. - Scientific reports 8: 5446.

[10] Ben-Horin, S., Chowers, Y. (2011): loss of response to anti-TNF treatments in Crohn's disease. - Alimentary Pharmacology \& Therapeutics 33: 987-995.

[11] Ben-Horin, S., Kopylov, U., Chowers, Y. (2014): Optimizing anti-TNF treatments in inflammatory bowel disease. - Autoimmunity reviews 13: 24-30.

[12] Billioud, V., Sandborn, W. J., Peyrin-Biroulet, L. (2011): Loss of response and need for adalimumab dose intensification in Crohn's disease: a systematic review. - The American Journal of Gastroenterology 106: 674.

[13] Brandse, J. F., Van den Brink, G. R., Wildenberg, M. E., Van der Kleij, D., Rispens, T., Jansen, J. M., Mathôt, R. A., Ponsioen, C. Y., Löwenberg, M., D’haens, G. R. (2015): Loss of infliximab into feces is associated with lack of response to therapy in patients with severe ulcerative colitis. - Gastroenterology 149: 350-355. e2.

[14] Busquets, D., Mas-de-Xaxars, T., López-Siles, M., Martínez-Medina, M., Bahí, A., Sàbat, M., Louvriex, R., Miquel-Cusachs, J. O., Garcia-Gil, J. L., Aldeguer, X. (2015): Antitumour necrosis factor treatment with adalimumab induces changes in the microbiota of Crohn's disease. - Journal of Crohn's and Colitis 9: 899-906.

[15] Castro-Laria, L., Argüelles-Arias, F., García-Sánchez, V., Benítez, J. M., Fernández-Pérez, R., Trapero-Fernández, A. M., Gallardo-Sánchez, F., Pallarés-Manrique, H., GómezGarcía, M., Cabello-Tapia, M. J. (2016): Initial experience with golimumab in clinical practice for ulcerative colitis. - Revista Española de Enfermedades Digestivas 108: 129132.

[16] Chaparro, M., Panes, J., García, V., Mañosa, M., Esteve, M., Merino, O., Andreu, M., Gutierrez, A., Gomollón, F., Cabriada, J. L. (2011): Long-term durability of infliximab treatment in Crohn's disease and efficacy of dose "escalation" in patients losing response. - Journal of Clinical Gastroenterology 45: 113-118.

[17] Chiodini, R. J., Dowd, S. E., Davis, B., Galandiuk, S., Chamberlin, W. M., Kuenstner, J. T., Mccallum, R. W., Zhang, J. (2013): Crohn's disease may be differentiated into 2 distinct biotypes based on the detection of bacterial genomic sequences and virulence genes within submucosal tissues. - Journal of Clinical Gastroenterology 47: 612-620.

[18] Ciccia, F., Rizzo, A., Triolo, G. (2016): Subclinical gut inflammation in ankylosing spondylitis. - Current Opinion in Rheumatology 28: 89-96.

[19] Cohen, R. D., Lewis, J. R., Turner, H., Harrell, L. E., Hanauer, S. B., Rubin, D. T. (2011): Predictors of adalimumab dose escalation in patients with Crohn's disease at a tertiary referral center. - Inflammatory Bowel Diseases 18: 10-16.

[20] Cohen, S. H., Gerding, D. N., Johnson, S., Kelly, C. P., Loo, V. G., Mcdonald, L. C., Pepin, J., Wilcox, M. H. (2010): Clinical practice guidelines for Clostridium difficile infection in adults: 2010 update by the society for healthcare epidemiology of America (SHEA) and 
the infectious diseases society of America (IDSA). - Infection Control \& Hospital Epidemiology 31: 431-455.

[21] Colombel, J. F., Sandborn, W. J., Rutgeerts, P., Enns, R., Hanauer, S. B., Panaccione, R., Schreiber, S., Byczkowski, D., Li, J., Kent, J. D. (2007): Adalimumab for maintenance of clinical response and remission in patients with Crohn's disease: the CHARM trial. Gastroenterology 132: 52-65.

[22] Colombel, J. F., Sandborn, W. J., Reinisch, W., Mantzaris, G. J., Kornbluth, A., Rachmilewitz, D., Lichtiger, S., D’haens, G., Diamond, R. H., Broussard, D. L. (2010): Infliximab, azathioprine, or combination therapy for Crohn's disease. - New England Journal of Medicine 362: 1383-1395.

[23] Colombel, J. F., Reinisch, W., Mantzaris, G., Kornbluth, A., Rutgeerts, P., Tang, K., Oortwijn, A., Bevelander, G., Cornillie, F., Sandborn, W. (2015): Randomised clinical trial: deep remission in biologic and immunomodulator naïve patients with Crohn's disease-a SONIC post hoc analysis. - Alimentary Pharmacology \& Therapeutics 41: 734746.

[24] Cornillie, F., Hanauer, S. B., Diamond, R. H., Wang, J., Tang, K. L., Xu, Z., Rutgeerts, P., Vermeire, S. (2014): Postinduction serum infliximab trough level and decrease of Creactive protein level are associated with durable sustained response to infliximab: a retrospective analysis of the ACCENT I trial. - Gut 63: 1721-1727.

[25] Coutinho, A., Kazatchkine, M. D., Avrameas, S. (1995): Natural autoantibodies. - Current Opinion in Immunology 7: 812-818.

[26] Coyte, K. Z., Schluter, J., Foster, K. R. (2015): The ecology of the microbiome: networks, competition, and stability. - Science 350: 663-666.

[27] Danese, S., Fiorino, G., Reinisch, W. (2011): causative factors and the clinical management of patients with Crohn's disease who lose response to anti-TNF- $\alpha$ therapy. - Alimentary Pharmacology \& Therapeutics 34: 1-10.

[28] Dassopoulos, T. (2005): When the love is lost: adalimumab for patients with an attenuated response to infliximab. - Inflammatory Bowel Diseases 11: 948-949.

[29] Ding, N., Hart, A., De Cruz, P. (2016): Systematic review: predicting and optimising response to anti-TNF therapy in Crohn's disease-algorithm for practical management. Alimentary Pharmacology \& Therapeutics 43: 30-51.

[30] Dubin, K., Callahan, M. K., Ren, B., Khanin, R., Viale, A., Ling, L., No, D., Gobourne, A., Littmann, E., Huttenhower, C. (2016): Intestinal microbiome analyses identify melanoma patients at risk for checkpoint-blockade-induced colitis. - Nature Communications 7: 10391.

[31] Ebert, E., Das, K., Mehta, V., Rezac, C. (2008): Non-response to infliximab may be due to innate neutralizing anti-tumour necrosis factor- $\alpha$ antibodies. - Clinical \& Experimental Immunology 154: 325-331.

[32] Echarri, A., Ferreiro, R., Fraga-Iriso, R., Barreiro-de Acosta, M., Cid, J., De-Castro, L., Pereira, S., Fernández-Villaverde, A., Soto, S., Carpio, D. (2014): Sa1264 drug trough levels and primary nonresponse to antiTNF therapy in moderate-severe Crohn disease. Results of the optimiza study. - Gastroenterology 146: S-247.

[33] Eckburg, P. B., Bik, E. M., Bernstein, C. N., Purdom, E., Dethlefsen, L., Sargent, M., Gill, S. R., Nelson, K. E., Relman, D. A. (2005): Diversity of the human intestinal microbial flora. - Science 308: 1635-1638.

[34] Erickson, A. R., Cantarel, B. L., Lamendella, R., Darzi, Y., Mongodin, E. F., Pan, C., Shah, M., Halfvarson, J., Tysk, C., Henrissat, B. (2012): Integrated metagenomics/metaproteomics reveals human host-microbiota signatures of Crohn's disease. - PloS One 7: e49138.

[35] Fasanmade, A. A., Adedokun, O. J., Ford, J., Hernandez, D., Johanns, J., Hu, C., Davis, H. M., Zhou, H. (2009): Population pharmacokinetic analysis of infliximab in patients with ulcerative colitis. - European Journal of Clinical Pharmacology 65: 1211. 
[36] Fasanmade, A. A., Adedokun, O. J., Blank, M., Zhou, H., Davis, H. M. (2011): Pharmacokinetic properties of infliximab in children and adults with Crohn's disease: a retrospective analysis of data from 2 phase III clinical trials. - Clinical therapeutics 33: 946-964.

[37] Ford, A. C., Sandborn, W. J., Khan, K. J., Hanauer, S. B., Talley, N. J., Moayyedi, P. (2011): Efficacy of biological therapies in inflammatory bowel disease: systematic review and meta-analysis. - The American Journal of Gastroenterology 106: 644.

[38] Gagnière, J., Raisch, J., Veziant, J., Barnich, N., Bonnet, R., Buc, E., Bringer, M.-A., Pezet, D., Bonnet, M. (2016): Gut microbiota imbalance and colorectal cancer. - World Journal of Gastroenterology 22: 501.

[39] Gisbert, J., Marín, A., Mcnicholl, A., Chaparro, M. (2015): Systematic review with metaanalysis: the efficacy of a second anti-TNF in patients with inflammatory bowel disease whose previous anti-TNF treatment has failed. - Alimentary Pharmacology \& Therapeutics 41: 613-623.

[40] Gomollón, F., Dignass, A., Annese, V., Tilg, H., Van Assche, G., Lindsay, J. O., PeyrinBiroulet, L., Cullen, G. J., Daperno, M., Kucharzik, T. (2016): 3rd European evidencebased consensus on the diagnosis and management of Crohn's disease 2016: part 1: diagnosis and medical management. - Journal of Crohn's and Colitis 11: 3-25.

[41] Grover, Z., Biron, R., Carman, N., Lewindon, P. (2014): Predictors of response to Infliximab in children with luminal Crohn's disease. - Journal of Crohn's and Colitis 8: 739-746.

[42] Ha, C., Ullman, T. A., Siegel, C. A., Kornbluth, A. (2012): Patients enrolled in randomized controlled trials do not represent the inflammatory bowel disease patient population. Clinical Gastroenterology and Hepatology 10: 1002-1007.

[43] Hanauer, S. B., Feagan, B. G., Lichtenstein, G. R., Mayer, L. F., Schreiber, S., Colombel, J. F., Rachmilewitz, D., Wolf, D. C., Olson, A., Bao, W. (2002): Maintenance infliximab for Crohn's disease: the ACCENT I randomised trial. - The Lancet 359: 1541-1549.

[44] Hazlewood, G. S., Rezaie, A., Borman, M., Panaccione, R., Ghosh, S., Seow, C. H., Kuenzig, E., Tomlinson, G., Siegel, C. A., Melmed, G. Y. (2015): Comparative effectiveness of immunosuppressants and biologics for inducing and maintaining remission in Crohn's disease: a network meta-analysis. - Gastroenterology 148: 344-354. e5.

[45] Honda, K., Littman, D. R. (2012): The microbiome in infectious disease and inflammation. - Annual Review of Immunology 30: 759-795.

[46] Juillerat, P., Sokol, H., Froehlich, F., Yajnik, V., Beaugerie, L., Lucci, M., Burnand, B., Macpherson, A. J., Cosnes, J., Korzenik, J. R. (2014): Factors associated with durable response to infliximab in Crohn's disease 5 years and beyond: a multicenter international cohort. - Inflammatory Bowel Diseases 21: 60-70.

[47] Karmiris, K., Paintaud, G., Noman, M., Magdelaine-Beuzelin, C., Ferrante, M., Degenne, D., Claes, K., Coopman, T., Van Schuerbeek, N., Van Assche, G. (2009): Influence of trough serum levels and immunogenicity on long-term outcome of adalimumab therapy in Crohn's disease. - Gastroenterology 137: 1628-1640.

[48] Keizer, R. J., Huitema, A. D., Schellens, J. H., Beijnen, J. H. (2010): Clinical pharmacokinetics of therapeutic monoclonal antibodies. - Clinical Pharmacokinetics 49: 493-507.

[49] Kiss, L., Szamosi, T., Molnar, T., Miheller, P., Lakatos, L., Vincze, A., Palatka, K., Barta, Z., Gasztonyi, B., Salamon, A. (2011): Early clinical remission and normalisation of CRP are the strongest predictors of efficacy, mucosal healing and dose escalation during the first year of adalimumab therapy in Crohn's disease. - Alimentary Pharmacology \& Therapeutics 34: 911-922.

[50] Leblanc, J., Laiño, J. E., Del Valle, M. J., Vannini, V. V., Van Sinderen, D., Taranto, M. P., De Valdez, G. F., De Giori, G. S., Sesma, F. (2011): B-Group vitamin production by lactic acid bacteria-current knowledge and potential applications. - Journal of Applied Microbiology 111: 1297-1309. 
[51] Ley, R. E., Hamady, M., Lozupone, C., Turnbaugh, P. J., Ramey, R. R., Bircher, J. S., Schlegel, M. L., Tucker, T. A., Schrenzel, M. D., Knight, R. 2008. Evolution of mammals and their gut microbes. -Science 320: 1647-1651.

[52] Lin, P., Bach, M., Asquith, M., Lee, A. Y., Akileswaran, L., Stauffer, P., Davin, S., Pan, Y., Cambronne, E. D., Dorris, M. (2014): HLA-B27 and human $\beta 2$-microglobulin affect the gut microbiota of transgenic rats. - PloS One 9: e105684.

[53] Lindsay, J. O., Armuzzi, A., Gisbert, J. P., Bokemeyer, B., Peyrin-Biroulet, L., Nguyen, G. C., Smyth, M., Patel, H. (2017): Indicators of suboptimal tumor necrosis factor antagonist therapy in inflammatory bowel disease. - Digestive and Liver Disease 49: 1086-1091.

[54] Louis, E., Boverie, J., Dewit, O., Baert, F., De, M. V., D'haens, G. (2007): Treatment of small bowel subocclusive Crohn's disease with infliximab: an open pilot study. - Acta Gastro-Enterologica Belgica 70: 15-19.

[55] Magnusson, M. K., Strid, H., Sapnara, M., Lasson, A., Bajor, A., Ung, K.-A., Öhman, L. (2016): Anti-TNF therapy response in patients with ulcerative colitis is associated with colonic antimicrobial peptide expression and microbiota composition. - Journal of Crohn's and Colitis 10: 943-952.

[56] Moran, G. W., Dubeau, M. F., Kaplan, G. G., Yang, H., Seow, C. H., Fedorak, R. N., Dieleman, L. A., Barkema, H. W., Ghosh, S., Panaccione, R. (2014): Phenotypic features of Crohn's disease associated with failure of medical treatment. - Clinical Gastroenterology and Hepatology 12: 434-442. e1.

[57] Ordás, I., Feagan, B. G., Sandborn, W. J. (2012): Therapeutic drug monitoring of tumor necrosis factor antagonists in inflammatory bowel disease. - Clinical Gastroenterology and Hepatology 10: 1079-1087.

[58] Papamichael, K., Gils, A., Rutgeerts, P., Levesque, B. G., Vermeire, S., Sandborn, W. J., Vande Casteele, N. (2014): Role for therapeutic drug monitoring during induction therapy with TNF antagonists in IBD: evolution in the definition and management of primary nonresponse. - Inflammatory Bowel Diseases 21: 182-197.

[59] Papamichael, K., Vajravelu, R. K., Vaughn, B. P., Osterman, M. T., Cheifetz, A. S. (2018): Proactive infliximab monitoring following reactive testing is associated with better clinical outcomes than reactive testing alone in patients with inflammatory bowel disease. - Journal of Crohn's and Colitis 12: 804-810.

[60] Papamichael, K., Juncadella, A., Wong, D., Rakowsky, S., Sattler, L. A., Campbell, J. P., Vaughn, B. P., Cheifetz, A. S. (2019): Proactive therapeutic drug monitoring of adalimumab is associated with better long-term outcomes compared with standard of care in patients with inflammatory bowel disease. - Journal of Crohn's and Colitis 13: 976-981.

[61] Peng, L., Li, Z.-R., Green, R. S., Holzman, I. R., Lin, J. (2009): Butyrate enhances the intestinal barrier by facilitating tight junction assembly via activation of AMP-activated protein kinase in Caco-2 cell monolayers. - The Journal of Nutrition 139: 1619-1625.

[62] Phillips, R. (2015): Rheumatoid arthritis: microbiome reflects status of RA and response to therapy. - Nature Reviews Rheumatology 11: 502.

[63] Rajca, S., Grondin, V., Louis, E., Vernier-Massouille, G., Grimaud, J.-C., Bouhnik, Y., Laharie, D., Dupas, J.-L., Pillant, H., Picon, L. (2014): Alterations in the intestinal microbiome (dysbiosis) as a predictor of relapse after infliximab withdrawal in Crohn's disease. - Inflammatory Bowel Diseases 20: 978-986.

[64] Reinisch, W., Lofberg, R., Louis, E., Kron, M., Camez, A., Robinson, A., Pollack, P. F. (2009): T1215 Subanalysis of remission rates by duration of disease in adalimumab-treated patients with Crohn's disease: the care trial. - Gastroenterology 136: A-523-A-524.

[65] Reinisch, W., Sandborn, W. J., Hommes, D. W., D'haens, G., Hanauer, S., Schreiber, S., Panaccione, R., Fedorak, R. N., Tighe, M. B., Huang, B. (2011): Adalimumab for induction of clinical remission in moderately to severely active ulcerative colitis: results of a randomised controlled trial. - Gut 60: 780-787.

[66] Rocha, C. S., Gomes-Santos, A. C., Moreira, T. G., De Azevedo, M., Luerce, T. D., Mariadassou, M., Delamare, A. P. L., Langella, P., Maguin, E., Azevedo, V. (2014): Local 
and systemic immune mechanisms underlying the anti-colitis effects of the dairy bacterium Lactobacillus delbrueckii. - PLoS One 9: e85923.

[67] Roda, G., Jharap, B., Neeraj, N., Colombel, J.-F. (2016): Loss of response to anti-TNFs: definition, epidemiology, and management. - Clinical and Translational Gastroenterology 7: e135.

[68] Rojas, J. R., Taylor, R. P., Cunningham, M. R., Rutkoski, T. J., Vennarini, J., Jang, H., Graham, M. A., Geboes, K., Rousselle, S. D., Wagner, C. L. (2005): Formation, distribution, and elimination of infliximab and anti-infliximab immune complexes in cynomolgus monkeys. - Journal of Pharmacology and Experimental Therapeutics 313: 578-585.

[69] Rooks, M. G., Veiga, P., Wardwell-Scott, L. H., Tickle, T., Segata, N., Michaud, M., Gallini, C. A., Beal, C., Van Hylckama-Vlieg, J. E., Ballal, S. A. (2014): Gut microbiome composition and function in experimental colitis during active disease and treatmentinduced remission. - The ISME Journal 8: 1403.

[70] Routy, B., Le Chatelier, E., Derosa, L., Duong, C. P., Alou, M. T., Daillère, R., Fluckiger, A., Messaoudene, M., Rauber, C., Roberti, M. P. (2018): Gut microbiome influences efficacy of PD-1-based immunotherapy against epithelial tumors. - Science 359: 91-97.

[71] Sandborn, W., Melmed, G., Mcgovern, D., Loftus Jr, E. V., Choi, J., Cho, J., Abraham, B., Gutierrez, A., Lichtenstein, G., Lee, S. (2015): Clinical and demographic characteristics predictive of treatment outcomes for certolizumab pegol in moderate to severe Crohn's disease: analyses from the 7-year PREC i SE 3 study. - Alimentary Pharmacology \& Therapeutics 42: 330-342.

[72] Sands, B. E., Anderson, F. H., Bernstein, C. N., Chey, W. Y., Feagan, B. G., Fedorak, R. N., Kamm, M. A., Korzenik, J. R., Lashner, B. A., Onken, J. E. (2004): Infliximab maintenance therapy for fistulizing Crohn's disease. - New England Journal of Medicine 350: 876-885.

[73] Sands, B. E., Feagan, B. G., Rutgeerts, P., Colombel, J.-F., Sandborn, W. J., Sy, R., D'haens, G., Ben-Horin, S., Xu, J., Rosario, M. (2014): Effects of vedolizumab induction therapy for patients with Crohn's disease in whom tumor necrosis factor antagonist treatment failed. - Gastroenterology 147: 618-627. e3.

[74] Schreiber, S., Colombel, J.-F., Bloomfield, R., Nikolaus, S., Schölmerich, J., Panés, J., Sandborn, W. J. (2010): Increased response and remission rates in short-duration Crohn's disease with subcutaneous certolizumab pegol: an analysis of PRECiSE 2 randomized maintenance trial data. - The American Journal of Gastroenterology 105: 1574.

[75] Sedger, L. M., Mcdermott, M. F. (2014): TNF and TNF-receptors: from mediators of cell death and inflammation to therapeutic giants-past, present and future. - Cytokine \& Growth Factor Reviews 25: 453-472.

[76] Sheehan, D., Moran, C., Shanahan, F. (2015): The microbiota in inflammatory bowel disease. - Journal of gastroenterology 50: 495-507.

[77] Singh, J. A., Wells, G. A., Christensen, R., Ghogomu, E. T., Maxwell, L. J., Macdonald, J. K., Filippini, G., Skoetz, N., Francis, D. K., Lopes, L. C. (2011): Adverse effects of biologics: a network meta-analysis and Cochrane overview. - Cochrane Database of Systematic Reviews. DOI: 10.1002/14651858.CD008794.pub2.

[78] Smith, P. M., Howitt, M. R., Panikov, N., Michaud, M., Gallini, C. A., Bohlooly, Y. M., Glickman, J. N., Garrett, W. S. (2013): The microbial metabolites, short-chain fatty acids, regulate colonic Treg cell homeostasis. - Science 341: 569-573.

[79] Sprakes, M. B., Ford, A. C., Warren, L., Greer, D., Hamlin, J. (2012): Efficacy, tolerability, and predictors of response to infliximab therapy for Crohn's disease: a large single centre experience. - Journal of Crohn's and Colitis 6: 143-153.

[80] Steenholdt, C. (2018): Proactive and reactive therapeutic drug monitoring of biologic therapies in inflammatory bowel disease are complementary, not mutually exclusive. Clinical Gastroenterology and Hepatology 16: 597-598. 
[81] Van Praet, L., Jacques, P., Van den Bosch, F., Elewaut, D. (2012): The transition of acute to chronic bowel inflammation in spondyloarthritis. - Nature Reviews Rheumatology 8: 288.

[82] Vermeire, S., Louis, E., Carbonez, A., Van Assche, G., Noman, M., Belaiche, J., De Vos, M., Van Gossum, A., Pescatore, P., Fiasse, R. (2002): Demographic and clinical parameters influencing the short-term outcome of anti-tumor necrosis factor (infliximab) treatment in Crohn's disease. - The American Journal of Gastroenterology 97: 2357.

[83] Wang, S., Ye, Q., Zeng, X., Qiao, S. (2019): Functions of macrophages in the maintenance of intestinal homeostasis. - Journal of Immunology Research. https://doi.org/10.1155/2019/1512969.

[84] Wang, Y., Gao, X., Ghozlane, A., Hu, H., Li, X., Xiao, Y., Li, D., Yu, G., Zhang, T. (2017): Characteristics of faecal microbiota in paediatric Crohn's disease and their dynamic changes during infliximab therapy. - Journal of Crohn's and Colitis 12: 337-346.

[85] Ward, M. M., Deodhar, A., Akl, E. A., Lui, A., Ermann, J., Gensler, L. S., Smith, J. A., Borenstein, D., Hiratzka, J., Weiss, P. F. (2016): American College of Rheumatology/Spondylitis Association of America/Spondyloarthritis Research and Treatment Network 2015 recommendations for the treatment of ankylosing spondylitis and nonradiographic axial spondyloarthritis. - Arthritis \& Rheumatology 68: 282-298.

[86] Wright, E. K., Kamm, M. A., Teo, S. M., Inouye, M., Wagner, J., Kirkwood, C. D. (2015): Recent advances in characterizing the gastrointestinal microbiome in Crohn's disease: a systematic review. - Inflammatory Bowel Diseases 21: 1219-1228.

[87] Zhang, X., Zhang, D., Jia, H., Feng, Q., Wang, D., Liang, D., Wu, X., Li, J., Tang, L., Li, Y. (2015): The oral and gut microbiomes are perturbed in rheumatoid arthritis and partly normalized after treatment. - Nature Medicine 21: 895. 